\title{
PENGGUNAAN METODE AHP DAN FAHP DALAM PENGUKURAN KUALITAS KEAMANAN WEBSITE E-COMMERCE
}

\author{
${ }^{1}$ Eza Rahmanita, ${ }^{2}$ Novi Prastiti, ${ }^{3}$ Ibnul Jazari \\ ${ }^{1}$ Teknik Informatika, Fakultas Teknik, Universitas Trunojoyo, Madura, Indonesia \\ ${ }^{2}$ Sistem Informasi, Fakultas Teknik, Universitas Trunojoyo, Madura, Indonesia \\ ${ }^{3}$ Teknik Informatika, Fakultas Teknik, Universitas Trunojoyo, Madura, Indonesia \\ Email: 1eza.rahmanita@trunojoyo.ac.id, 2prastitinovi@trunojoyo.ac.id, 33ibnul_jazari@yahoo.co.id
}

(Naskah masuk: 22 Mei 2018, diterima untuk diterbitkan: 7 Agustus 2018)

\begin{abstract}
Abstrak
Website e-commerce yang aman dapat melindungi informasi pengguna atau pelanggan. Sejumlah masalah keamanan e-commerce muncul seiring dengan bertambahnya transaksi. Pada penelitian ini kami menggunakan metode Analytic Hierarchy Process (AHP) dan Fuzzy Analytic Hierarchy Process (FAHP) dalam pengambilan keputusan. AHP sangat berguna sebagai alat dalam analisis pengambilan keputusan dan telah banyak digunakan dengan baik dalam berbagai bidang seperti evaluasi, assessment, peramalan, pemilihan karyawan, penilai konsep produk, dan lain-lain. Logika Fuzzy digunakan untuk variabel ketidakpastian atau samar, sedangkan AHP tepat dalam mempertimbangkan karakteristik baik kualitatif maupun kuantitatif yang lebih dekat dengan situasi nyata. Dari penelitian yang telah dilakukan diketahui bahwa situs Tokopedia.com sebagai $e$-commerce terbaik dalam segi keamanan website, karena semua e-commerce pada tools secure web test memperoleh nilai yang sama, dan pada tools asafa web menduduki peringkat 1 serta pada tools observatory menduduki peringkat 2 .
\end{abstract}

Kata kunci: website, e-commerce, $A H P, F A H P$

\section{THE USE OF AHP AND FAHP METHODS IN MEASURING THE QUALITY OF E- COMMERCE WEBSITE SECURITY}

\begin{abstract}
Website e-commerce which secure can protect the information of users or costumers. A number of security problem e-commerce appears along with transaction. In this research we used Analytic Hierarchy Process (AHP) and Fuzzy Analytic Hierarchy Process (FAHP) method. Ahp is very useful as tools in taking decision analysis and have used well in various areas such as evaluation, assessment, prediction, employee selection, concept's rating, product and etc. Logic of Fuzzy used to uncertainty variable or vague, whereas AHP exact in consider the characteristic even if qualitative and quantitative which nearer with the real situation. From the research that has done, it is known that the site of Tokopedia.com as e-commerce is the best in website security side, because all of e-commerce at tools secure web test gained the same value, and at tools asafa web occupy ranking 1, and at tools observatory occupy ranking 2.
\end{abstract}

Keywords: website, e-commerce, AHP, FAHP

\section{PENDAhuluan}

Menurut Siregar dalam Irmawati menjelaskan bahwa "Electronic Commerce (e-commerce) adalah proses pembelian, penjualan atau tukar produk, jasa dan informasi melalui jaringan komputer". $E$ Commerce merupakan bagian dari e-business, di mana cakupan e-business lebih luas, tidak hanya sekedar perniagaan tetapi mencakup juga pengolaborasian mitra bisnis, pelayanan nasabah, lowongan pekerjaan, dll. Selain teknologi jaringan www, e-commerce juga memerlukan teknologi basis data atau pangkalan data (database), e-surat atau surat elektronik (e-mail), dan bentuk teknologi non komputer yang lain seperti halnya sistem pengiriman barang, dan alat pembayaran untuk e-commerce ini. Dalam mengimplementasikan e-commerce tersedia suatu integrasi rantai nilai dari infrastrukturnya, yang terdiri dari tiga lapis. Pertama, insfrastruktur sistem distribusi (flow of good), kedua, insfrastruktur pembayaran (flow of money), dan ketiga, infrastruktur sistem informasi (flow of information). Agar dapat terintegrasi dengan sistem rantai supplay dari supplier, ke pabrik, ke gudang, distribusi, jasa transportasi, hingga ke pelanggan maka diperlukan integrasi enterprise system untuk menciptakan supply 
chain visibility. Ada tiga faktor yang patut dicermati oleh kita jika ingin membangun toko e-commerce yaitu: variability, visibility, dan velocity (Irmawati, 2011).

Di Indonesia, banyak usaha B2C yang memanfaatkan internet dan teknologi informasi dalam pemasaran produknya, seperti toko buku Gramedia, toko busana muslim Rabbani, dan lainlain. Implementasi konsep B2C biasanya melalui pembuatan website e-commerce yang digunakan untuk bertransaksi secara langsung dengan konsumen. Website e-commerce membuat jangkauan pasar sebuah usaha menjadi lebih global. Website $e$ commerce pun telah menjadi sesuatu yang sangat penting bagi banyak industri, khususnya Usaha Kecil Menengah (UKM) dalam berinteraksi dengan stakeholder dan konsumen (Merwe \& Bekker, 2003).

Situs e-commerce saat ini bergerak jauh melampaui penggunaan awal, situs web komersil secara efektif sebagai sebuah "jendela belanja" elektronik, dengan pengunjung bisa melihat produk dan jasa yang tersedia, tetapi tidak dapat membeli secara langsung. Selanjutnya berfungsi untuk meningkatkan persyaratan keamanan, karena masalah pribadi yang sensitif dan rincian keuangan diberikan secara berkala ketika melakukan transaksi. Sejumlah masalah keamanan harus dipertimbangkan untuk meningkatkan keamanan seluruh website $e$ commerce.

Beberapa penelitian keamanan situs web $e$ commerce difokuskan pada solusi keamanan situs web e-commerce. Menurut Zuccato dalam Samuel Ongkowijoyo mungusulkan suatu pendekatan untuk memperoleh persyaratan keamanan dan kemudian mengembangkan sebuah kerangka manajemen keamanan untuk meningkatkan keamanan situs web e-commerce. Kelebihan penelitian ini adalah memiliki faktor-faktor keamanan e-commerce yang terdiri dari 27 kriteria keamanan dan menggunakan metode yang cukup kompleks yaitu kombinasi metode AHP, Dempster-Shafer dan Fuzzy TOPSIS sedangkan kekurangannya adalah kesulitan mencari narasumber yang expert dalam bidang keamanan $e$ commerce (Ongkowijoyo, 2013).

Penelitian Reza Rahardian, Nurul Hidayat dan Ratih Kartika Dewi pada tahun 2018 yang berjudul "Sistem Pendukung Keputusan Penentuan Penerima Bantuan Keluarga Miskin Menggunakan Metode Analytical Hierarchy Process - Preference Ranking Organization for Enrichment Evaluaion II (AHPPROMETHEE II)", pada penelitian ini dijelaskan bahwa Metode AHP-PROMETHEE II diimplementasikan dengan cara menentukan bobot awal yang akan digunakan dalam proses metode AHP. Dengan bobot yang telah ditentukan, akan menghasilkan vektor bobot yang akan dihasilkan oleh proses AHP. Vektor bobot tersebut akan digunakan sebagai acuan dimana bobot tersebut akan digunakan sebagai acuan dalam perhitungan PROMETHEE II. Untuk mengimplementasikan PROMETHEE II, diperlukan data dengan atribut sesuai dengan bobot yang telah ditentukan dengan AHP. Setelah data dimasukkan, proses PROMETHEE II akan berlangsung dan pada PROMETHEE II akan dihasilkan data yang telah dirankingkan (Rahardian, Hidayat, \& Dewi, 2018).

Penelitian Sri Huning Anwariningsih pada tahun 2010 yang berjudul "Multi Faktor Kualitas Website", pada penelitian ini dijelaskan bahwa dari sisi kualitas website ada beberapa hal yang harus diperhatikan, di antaranya adalah sisi desain, informasi/content, sisi usefulness, dan sisi communicatif. Masing-masing faktor kualitas tersebut harus diselaraskan dengan faktor kualitas perancangan sebuah perangkat lunak (Anwariningsih).

Penelitian Yeni kustiyahningsih, eza rahmanita, jakapurnama (2016) dalam penelitian yang berjudul "integration balanced scoredcard and fuzzy analytic network process (fanp) for measuring performance of small medium enterprise (sme)", tujuan dari penelitian ini adalah untuk menentukan standar atau pengukuran kinerja UKM sesuai dengan kebutuhan dan kondisi di Bangkalan, model pengambilan keputusan yang dibangun menggunakan MCDM, metode yang digunakan adalah Fuzzy Analytic Network Process (FANP) sebagai solusi pada kompleksitas dan kurangnya kejelasan dalam kriteria penilaian untuk mengukur indikator kinerja, untuk mengukur kinerja secara keseluruhan sesuai dengan perspektif balanced scorecard, yaitu pelanggan, keuangan, bisinis internal, pembelajaran dan pertumbuhan, dan TOPSIS untuk menentukan peringkat atau perengkingan (Kustiyahningsi \& dkk, 2016).

Dari permasalahan diatas maka metode untuk penyelesaian yang ditawarkan adalah Fuzzy Analytic Hierarchy Process (FAHP). Karena Fuzzy AHP (FAHP) merupakan ekstensi dari AHP dengan mengkombinasikan teori logika fuzzy. Pada FAHP, skala rasio fuzzy digunakan untuk mengindikasikan kekuatan relatif dari faktor-faktor pada kriteria yang bersangkutan. Sehingga, sebuah matriks keputusan fuzzy dapat dibentuk. Nilai akhir dari alternatifalternatif juga disajikan dalam angka-angka fuzzy. Proses transformasi logika fuzzy terhadap AHP pada penelitian ini dilakukan dengan mengikuti metode yang dikembangkan oleh Saaty. Operasi matriks perbandingan pairwise dilakukan dengan menggunakan Tringular Fuzzy Number (TFN), yang merupakan kelas khusus bilangan fuzzy yang keanggotaannya didefinisikan oleh tiga bilangan real yang diekspresikan sebagai (low, middle, upper) (Chang, 1996).

Penelitian ini diharapkan dapat menguukur seberapa akurat metode Fuzzy Analytic Hierarchy Process (FAHP) untuk mengukur akurasi kualitas keamanan website e-commerce sehingga dapat melindungi e-business dan informasi pengguna atau pelanggan tetap aman. 


\section{METODE}

\subsection{ANALYTIC HIERARCHY PROCESS}

Analytic Hierarchy Process (AHP) adalah salah satu metode khusu dari Multi Criteria Decision Making (MCDM) yang diperkenalkan oleh Saaty tahun 2001, AHP sangat berguna sebagai alat dalam analisis pengambilan keputusan dan telah banyak digunakan dengan baik dalam berbagai bidang seperti evaluasi, assessment, peramalan, pemilihan karyawan, penilai konsep produk, dan lain-lain. Pada dasarnya, metode AHP memecah-mecah suatu situasi yang kompleks dan tak terstruktur ke dalam bagianbagian komponennya. Kemudian menata bagian atau variabel ini dalam suatu susunan hirarki dan memberi nilai numerik pada pertimbangan subjektif tentang relatif pentingnya setiap variabel. Setalah itu mensintesis berbagai pertimbangan ini untuk menetapkan variable mana yang memliki prioritas paling tinggi dan bertindak untuk mempengaruhi hasil pada situasi tersebut (Faisol, Muslim, \& Suyono, 2014).

AHP memiliki landasan aksiomatik yang terdiri dari (Faisol, Muslim, \& Suyono, 2014):

a. Reciprocal Comparison, yang mengandung arti bahwa matriks perbandingan berpasangan yang terbentuk harus bersifat berkebalikan. Misalnya, jika A adalah $k$ kali lebih penting dari pada B maka B adalah $1 / k$ kali lebih penting dari A

b. Homogenity, yaitu mengandung arti kesamaan dalam melakukan perbandingan. Misalnya, tidak dimungkinkan membandingkan jeruk dengan bola tenis dalam hal rasa, akan tetapi lebih relevan jika membandingkan dalam hal berat.

c. Dependence, yang berarti setiap level mempunyai kaitan (complete hierarchy) walaupun mungkin saja terjadi hubungan yang tidak semputna (incomplete hierarchy).

d. Expection, yang berarti menonjolkan penilaian yang bersifat ekspektasi (harapan) dan preferensi dari pengambilan keputusan. Penilaian dapat merupakan data kuantitatif (angka) maupun yang bersifat kualitatif.

Dalam menyelesaikan persoalan dengan Metode AHP, ada beberapa prinsip dasar yang harus dipahami, yakni :

1. Decomposition (prinsip menyusun hirarki)

Decomposition adalah memecahkan atau membagi problem yang utuh menjadi unsur-unsurnya ke dalam bentuk hirarki proses pengambilan keputusan, dimana setiap unsur atau elemen saling berhubungan. Untuk mendapatkan hasil yang akurat, pemecahan dilakukan terhada unsur-unsur sampai tidak mungkin dilakukan pemecahan lebih lanjut, sehingga didapatkan beberapa tingkatan dari persoalan yang hendak dipecahkan. Struktur hirarki keputusan tersebut dapat dikategorikan sebagai complete dan incomplete. Suatu hirarki keputusan disebut complete jika semua elemen pada suatu tingkat memiliki hubungan terhadap semua elemen yang ada pada tingkat berikutnya (Gambar 1), sementara pada hirarki keputusan incomplete tidak semua unsur pada masing-masing jenjang mempunyai hubungan. Pada umumnya problem nyata mempunyai karakteristik struktur yang incomplete.

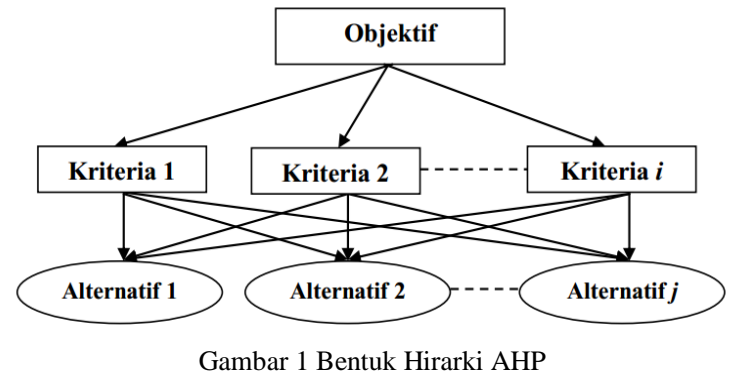

2. Comporative Judgement

Comporative Judgement dilakukan dengan penilaian tentang kepentingan relatif dua elemen pada suatu tingkat tertentu dalam kaitannya dengan tingkatan di atasnya. Penilaian ini merupakan inti dari AHP Karena akan berpengaruh terhadap urutan prioritas dari elemen-elemennya. Hasil dari penilaian ini lebih mudah disajikan dalam bentuk mtariks pairwise comparison yaitu matriks perbandingan berpasangan memuat tingkat preferensi beberapa alternatif untuk tiap kriteria skala preferensi yang digunakan yaitu skala 1 yang menunjukkan tingkat yang paling rendah (equal importance) sampai dengan skala 9 yang menunjukkan tinkatan yang paling tinggi (extreme importance).

3. Synthesis of Priority

Synthesis of Priority dilakukan dengan menggunakan eigen vector method untuk mendapatkan bobot relatif bagi unsur-unsur pengambilan keputusan.

\section{Logical Consistency}

Logical Consistency merupakan karakteristik penting AHP. Hal ini dicapai dengan mengagresikan seluruh eigen vector yang diperoleh dari berbagai tingkatan hirarki dan selanjutnya diperoleh suatu vector composite tertimbang yang menghasilkan urutan pengambilan keputusan.

Langkah-langkah pengerjaan AHP adalah sebagai berikut (Faisol, Muslim, \& Suyono, 2014):

a. Menganalisa permasalahan ril dalam struktur hirarki atas unsur-unsur pendukungnya.

b. membuat penilaian tentang kepentingan relatif antara dua elemen yang disajikan dalam bentuk matriks perbandingan dengan menggunakan skala prioritas. Jika terdapat $n$ elemen maka akan diperoleh matriks pairwise comparison (perbandingan berpasangan) pada persamaan 1 berdimensi $n \times n$, dan banyaknya penilaian yang diperlukan adalah sebanyak $n(n-1) / 2$. Tahapan yang dilakukan dalam penilaian terhadap elemen-elemen yang dibandingkan adalah : (1) elemen mana yang lebih penting / berpengaruh / 
disukai, (2) Berapa kali lebih penting / berpengaruh / disukai suatu elemen dari pada elemen lainnya.

$$
A=\left[\begin{array}{ccccc}
a_{11} & a_{12} & a_{13} & \ldots & a_{1 n} \\
a_{21} & a_{22} & a_{23} & \ldots & a_{2 n} \\
a_{31} & a_{32} & a_{33} & \ldots & a_{3 n} \\
\vdots & \vdots & \vdots & & \vdots \\
a_{n 1} & a_{n 2} & a_{n 2} & \ldots & a_{n n}
\end{array}\right]
$$

Menghitung konsistensi Matriks A sebagai berikut :

Normalisasi Matriks

$$
\begin{gathered}
W=\left[\begin{array}{cccc}
w_{11} & w_{12} & \ldots & w_{1 n} \\
w_{21} & w_{22} & \cdots & w_{2 n} \\
\vdots & \vdots & & \vdots \\
w_{n 1} & w_{n 2} & \cdots & w_{n n}
\end{array}\right] \\
=\left[\begin{array}{cccc}
\frac{a_{11}}{\sum_{i=1}^{n} a_{i 1}} & \frac{a_{12}}{\sum_{i=1}^{n} a_{i 2}} & \cdots & \frac{a_{1 n}}{\sum_{i=1}^{n} a_{i n}} \\
\frac{a_{21}}{\sum_{i=1}^{n} a_{i 1}} & \frac{a_{22}}{\sum_{i=1}^{n} a_{i 2}} & \cdots & \frac{a_{2 n}}{\sum_{i=1}^{n} a_{i n}} \\
\vdots & \vdots & \cdots & \vdots \\
\frac{a_{n 1}}{\sum_{i=1}^{n} a_{n 1}} & \frac{a_{n 2}}{\sum_{i=1}^{n} a_{n 2}} & \cdots & \frac{a_{n n}}{\sum_{i=1}^{n} a_{n n}}
\end{array}\right]
\end{gathered}
$$

Menghitung rata-rata matriks yang sudah di normalisasi

$$
A R=\left[\begin{array}{l}
a r_{11} \\
a r_{21} \\
\vdots \\
a r_{n 1}
\end{array}\right]=\left[\begin{array}{l}
\frac{\sum_{i=1}^{n} W_{1 i}}{n} \\
\frac{\sum_{i=1}^{n} W_{2 i}}{n} \\
\vdots \\
\frac{\sum_{i=1}^{n} W_{n i}}{n}
\end{array}\right]
$$

Perkalian Matrik awal (A) dengan rata-rata (AR)

$$
\begin{gathered}
B=\left[\begin{array}{cccc}
b_{11} & b_{12} & \ldots & b_{1 n} \\
b_{21} & b_{22} & \ldots & b_{2 n} \\
\vdots & \vdots & & \vdots \\
b_{n 1} & b_{n 2} & \ldots & b_{n n}
\end{array}\right] \\
=\left[\begin{array}{cccc}
a_{11} \cdot a r_{11} & a_{12} \cdot a r_{21} & \ldots & a_{1 n} \cdot a r_{n 1} \\
a_{21} \cdot a r_{11} & a_{22} \cdot a r_{21} & \ldots & a_{2 n} \cdot a r_{n 1} \\
\vdots & \vdots & & \vdots \\
a_{n 1} \cdot a_{11} & a_{n 2} \cdot a r_{21} & \ldots & a_{n n} \cdot a r_{n 1}
\end{array}\right]
\end{gathered}
$$

Penjumlahan tiap baris pada matriks diatas :

$$
C=\left[\begin{array}{l}
\sum_{i=1}^{n} b_{11} \\
\sum_{i=1}^{n} b_{2 i} \\
\vdots \\
\sum_{i=3}^{n} b_{n i}
\end{array}\right]
$$

Keterangan :

$\mathrm{AR}=$ Matriks rata-rata

$\mathrm{W}=$ bobot matriks

$\mathrm{B}=$ Matrik Perkalian Elemen A dengan AR

$\mathrm{C}=$ Jumlah tiap baris matriks B

Untuk menguji konsistensi matriks perbandingan berpasangan tiap responden perlu dicari nilai $\lambda_{\text {maks }}$, CI, CR.

$$
\lambda_{\text {maks }}=\sum_{i=1}^{n} \frac{c_{i 1}}{\frac{a r_{i 1}}{n}}
$$

Untuk menghitung CI yaitu :

$$
C I=\frac{\lambda_{\text {maks }}-n}{n-1}
$$

\begin{tabular}{|c|c|c|c|c|c|c|c|c|c|c|}
\hline $\begin{array}{l}\text { Ordo } \\
\text { Matr } \\
i k\end{array}$ & 1 & 2 & 3 & 4 & 5 & 6 & 7 & 8 & 9 & 10 \\
\hline $\begin{array}{l}\text { Inde } \\
x \\
\text { Rand } \\
\text { om }\end{array}$ & 0 & 0 & 0,58 & 0,90 & 1,12 & 1,32 & 1,41 & 1,49 & $\begin{array}{c}1,5 \\
1\end{array}$ & $\begin{array}{c}1,4 \\
9\end{array}$ \\
\hline
\end{tabular}

Untuk menghitung CR yaitu :

$$
C R=\frac{C I}{I R}
$$

Keterangan :

$$
\begin{array}{ll}
\lambda_{\text {maks }} & =\text { eigen value maksimum } \\
\mathrm{CI} & =\text { Consistency Index } \\
\mathrm{CR} & =\text { Consistency Ratio } \\
\mathrm{IR} & =\text { Index Random } \\
\mathrm{n} & =\text { Banyaknya elemen yang dibandingkan }
\end{array}
$$

Dengan nilai random index (RI) pada Tabel 1 dibawah ini, yaitu :

Setelah matriks perbandingan berpasangan konsisten maka nilai dikonversikan menjadi triangular fuzzy number (TFN) dalam bentuk (low, middle, upper) seperti pada skala numerik dan skala linguistik untuk tingkat kepentingan. 


\subsection{FUZZY ANALYTIC PROCESS (FAHP)}

FAHP merupakan teori yang mengkombinasikan antara AHP dengan logika Fuzzy. Pada FAHP, skala rasio Fuzzy digunakan untuk mengindikasikan kekuatan relatif dari faktor-faktor pada kriteria yang bersangkutan. Nilai akhir dari kriteria juga disajikan dalam angka-angka Fuzzy. Proses transformasi logika Fuzzy terhadap AHP pada penelitian ini dilakukan dengan mengikuti metode yang dikembangkan oleh Gungor, et al., (2009). Operasi matriks perbandingan dilakukan dengan menggunakan Triangular Fuzzy Number (TFN), yang merupakan bilangan Fuzzy yang keanggotaannya didefinisikan tiga bilangan real sebagai low, middle, upper (Faisol, Muslim, \& Suyono, 2014).

Tabel 2 Skala Nilai Fuzzy Segitiga

\begin{tabular}{|c|c|c|c|}
\hline $\begin{array}{l}\text { Intensitas } \\
\text { Kepentinga } \\
\text { n AHP }\end{array}$ & $\begin{array}{l}\text { Himpunan } \\
\text { Linguistik }\end{array}$ & (TFN) & Reciprocal \\
\hline 1 & $\begin{array}{l}\text { Perbandingan } \\
\text { elemen yang sama }\end{array}$ & $(1,1,1)$ & $(1,1,1)$ \\
\hline 2 & Pertengahan & $\begin{array}{c}(1 / 2,1, \\
3 / 2)\end{array}$ & $(2 / 3,1,2)$ \\
\hline 3 & $\begin{array}{l}\text { Elemen satu cukup } \\
\text { penting dari yang } \\
\text { lainnya }\end{array}$ & $(1,3 / 2,2)$ & $(1 / 2,2 / 3,1)$ \\
\hline 4 & Pertengahan & $\begin{array}{c}(3 / 2,2 \\
5 / 2)\end{array}$ & $(2 / 5,1 / 2,2 / 3)$ \\
\hline 5 & $\begin{array}{l}\text { Elemen satu kuat } \\
\text { pentingnya dari } \\
\text { yang lain }\end{array}$ & $(2,5 / 2,3)$ & $(1 / 3,2 / 5,1 / 2)$ \\
\hline 6 & Pertengahan & $\begin{array}{c}(5 / 2,3, \\
7 / 2)\end{array}$ & $(2 / 7,1 / 3,2 / 5)$ \\
\hline 7 & $\begin{array}{l}\text { Elemen satu lebih } \\
\text { kuat pentingnya dari } \\
\text { yang lain }\end{array}$ & $(3,7 / 2,4)$ & $(1 / 4,2 / 7,1 / 3)$ \\
\hline 8 & Pertengahan & $\begin{array}{c}(7 / 2,4, \\
9 / 2)\end{array}$ & $(2 / 9,1 / 4,2 / 7)$ \\
\hline 9 & $\begin{array}{l}\text { Elemen satu mutlak } \\
\text { lebih penting dari } \\
\text { yang lainnya }\end{array}$ & $\begin{array}{c}(4,9 / 2 \\
9 / 2)\end{array}$ & $(2 / 9,2 / 9,1 / 4)$ \\
\hline
\end{tabular}

Adapun langkah dari FAHP adalah sebagai berikut (Faisol, Muslim, \& Suyono, 2014):

1. Konstruksi matriks perbandingan berpasangan berdasarkan kriteria dalam AHP. dapat didefinisikan sebagai berikut :

$$
\mathrm{X}=\left[\begin{array}{ccccc}
1 & x_{12} & x_{13} & \ldots & x_{1 n} \\
x_{21} & 1 & x_{23} & \ldots & x_{2 n} \\
x_{31} & x_{32} & 1 & \ldots & x_{3 n} \\
\vdots & \vdots & \vdots & \ddots & \vdots \\
x_{n 1} & x_{n 2} & x_{n 3} & \ldots & 1
\end{array}\right]
$$

dengan

$$
x_{i j}=\left(\mathrm{x}_{i j}^{l}, \mathrm{x}_{i j}^{m}, \mathrm{x}_{i j}^{u}\right), x_{i j}^{-1}=\left(\frac{1}{x_{i j}^{u}}, \frac{1}{x_{i j}^{m}}, \frac{1}{x_{i j}^{l}}\right)
$$

, dengan $i, j=1,2, \ldots n$.

1. Hitung rataan geometric

Hasil penilaian perbandingan berpasangan beberapa responden dihitung dengan rataan geometric. Perhitungan rataan geometric dinotasikan dengan matriks $\mathrm{S}$ sebagai berikut (Faisol, Muslim, \& Suyono, 2014):

$$
\begin{gathered}
\mathrm{S}=\left[\begin{array}{ccccc}
S_{11} & S_{12} & s_{13} & \ldots & S_{1 n} \\
S_{21} & S_{22} & s_{23} & \ldots & S_{2 n} \\
S_{31} & S_{32} & S_{33} & \ldots & S_{3 n} \\
\vdots & \vdots & \vdots & \ddots & \vdots \\
S_{n 1} & S_{n 2} & S_{n 3} & \ldots & S_{n n}
\end{array}\right] \\
s_{i j}=\left(\left(\prod_{k=1}^{n} \mathrm{x}_{i j k}^{l}\right)^{1 / n},\left(\prod_{k=1}^{n} \mathrm{x}_{i j k}^{m}\right)^{1 / n},\left(\prod_{k=1}^{n} \mathrm{x}_{i j k}^{u}\right)^{1 / n}\right),
\end{gathered}
$$

dengan $i, j=1,2, \ldots, n$.

2. Hitung bobot kriteria dari matriks $\mathrm{S}$.

Hasil bobot kriteria matriks $\mathrm{S}$ dinotasikan dengan U. Bobot kriteria untuk triangular fuzzy number sesuai dengan Gungor, et al., (2009) dapat dinyatakan sebagai berikut (Faisol, Muslim, \& Suyono, 2014):

$\mathrm{U}=\left[\begin{array}{c}u_{1} \\ u_{2} \\ u_{3} \\ \vdots \\ u_{n}\end{array}\right]$

$$
u_{i}=\left(\frac{\prod_{j=1}^{n}\left(s_{i j}^{l}\right)^{1 / n}}{\sum_{i=1}^{n} s_{i j}^{u}}, \frac{\prod_{j=1}^{n}\left(s_{i j}^{m}\right)^{1 / n}}{\sum_{i=1}^{n} s_{i j}^{m}}, \frac{\prod_{j=1}^{n}\left(s_{i j}^{u}\right)^{1 / n}}{\sum_{i=1}^{n} s_{i j}^{l}}\right)
$$

dengan $i, j=1,2, \ldots, n$.

3. Hitung defuzzyfikasi dari $u_{i}$

Defuzzyfikasi digunakan untuk mengubah output fuzzy menjadi nilai tegas / crisp dengan metode Best Nonfuzzy Performance (BNP). $B N P$ dapat dinyatakan sebagai berikut :

$$
B N P_{i}=\frac{\left(u_{i}^{u}-u_{i}^{l}\right)+\left(\mathrm{u}_{i}^{m}-u_{i}^{l}\right)}{3}+u_{i}^{l}
$$

dengan $i=1,2, \ldots, n$.

\section{PERANCANGAN SISTEM}


a. Flowchart Diagram FAHP

Flowchart Fuzzy AHP yang diawali dengan memasukkan data kriteria dan web e-commerce. Apabila data kriteria sudah diisi, maka lanjut ke skala penilaian dan menyusun matriks perbandingan berpasangan antar kriteria/subkriteria, selanjutnya tentukan batas TFN (low, middle, upper) dan konversi matriks perbandingan ke dalam skala TFN serta akan ternormalisasi, dan akan mendapatkan bobot kriteria, masukkan bobot e-commerce, prioritas matrik kriteria dikalikan dengan prioritas $e$ commerce, yang terakhir akan mendapatkan hasil perhitungan.

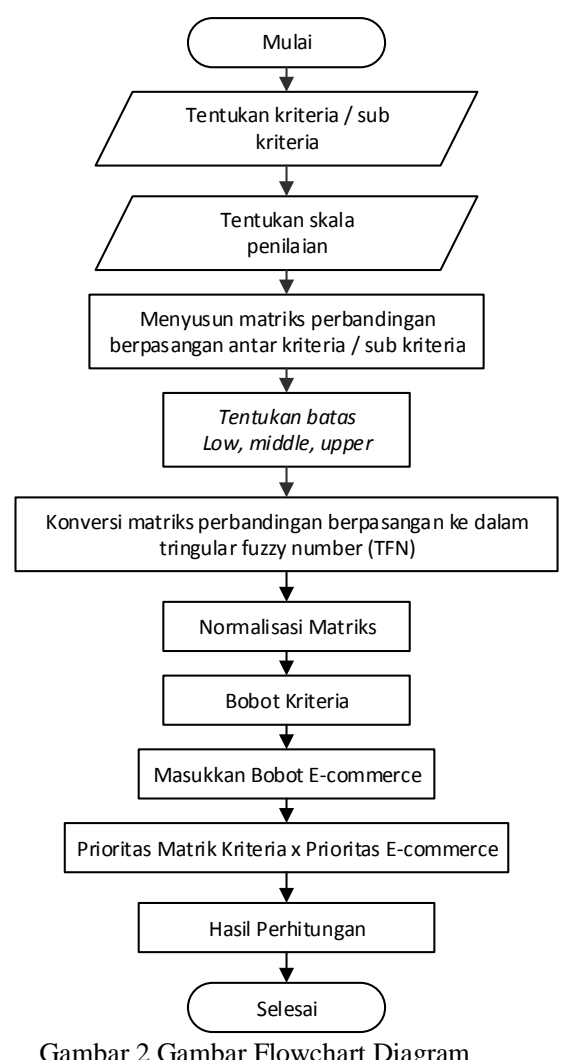

a. Comceptual Data Model (CDM)

CDM merupakan sebuah model yang dibuat yang didasari dengan anggapan bahwa dunia merupakan objek dan masing-masing objek tersebut memiliki hubungan. Manfaat menggunakan CDM antara lain yaitu dapat memberikan gambaran secara lengkap dari struktur database. Berikut merupakan gambaran CDM dari sistem.

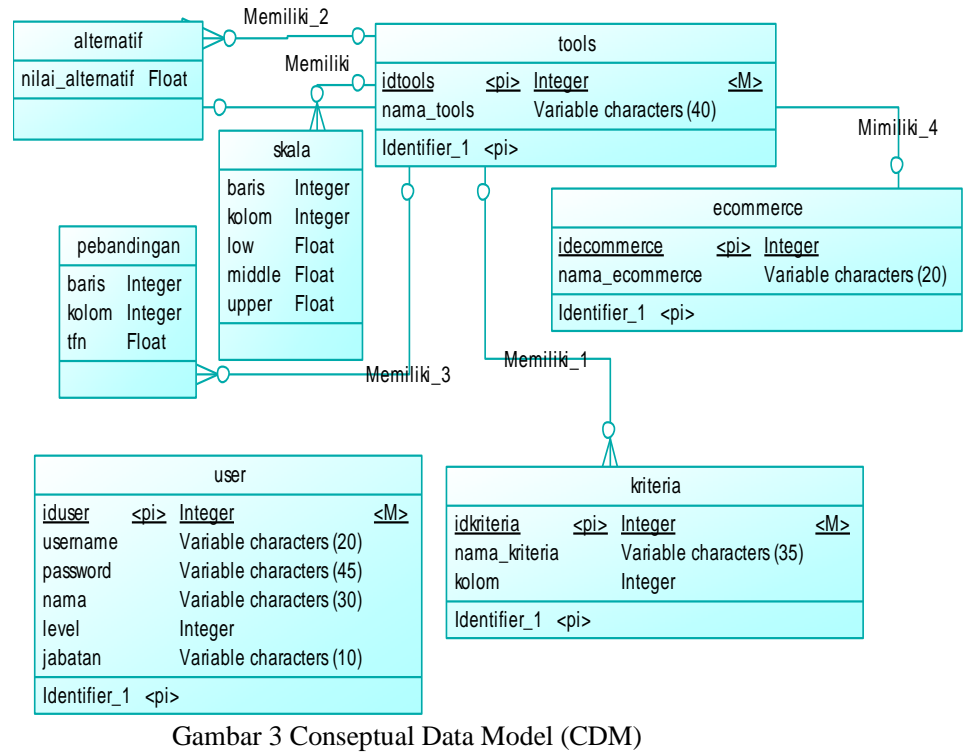

b. Physical Data Model (PDM)

PDM merupakan sebuah model yang menampilkan sejumlah tabel untuk menggambarkan data serta hubungan antar tabelnya. Setiap tabel memiliki sejumlah kolom dimana setiap kolom memiliki nama yang unik atau disebut dengan primary key. Berikut ini merupakan gambar model PDM.

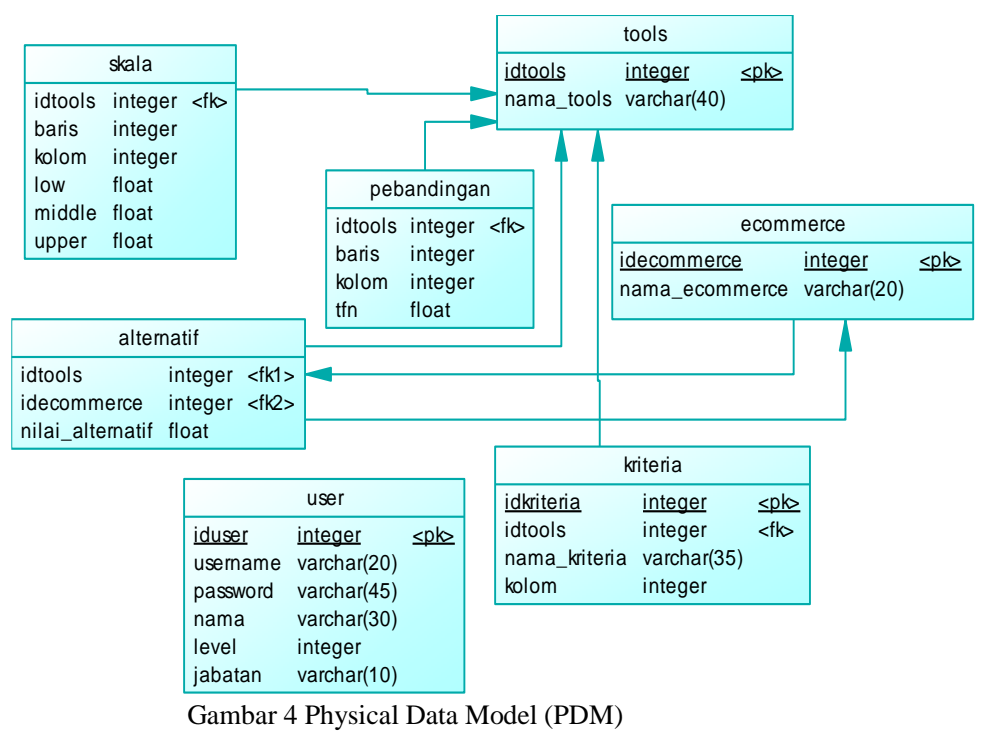

\section{IMPLEMENTASI DAN PEMBAHASAN}

a. Halaman Bobot Kriteria Tools Secure Web Test

Halaman bobot kriteria berfungsi ketika admin akan menambahkan perbandingan bobot masing-masing kriteria. Berikut adalah tampilan halaman bobot kriteria. 
囲 Skala Perbandingan Kriteria

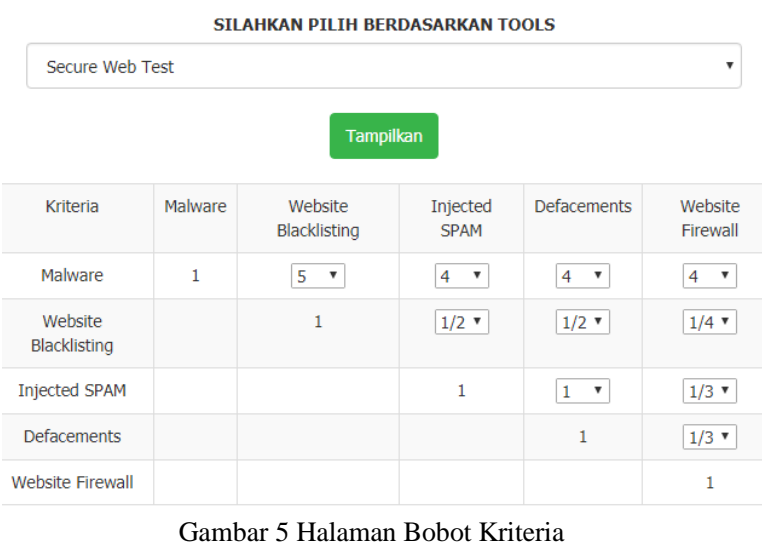

b. Halaman Bobot AHP

Halaman Bobot AHP berfungsi ketika admin akan melihat bobot perbandingan kriteria yang telah dimasukkan dan disimpan. Berikut adalah tampilan halaman bobot AHP.

团 Perbandingan Kriteria

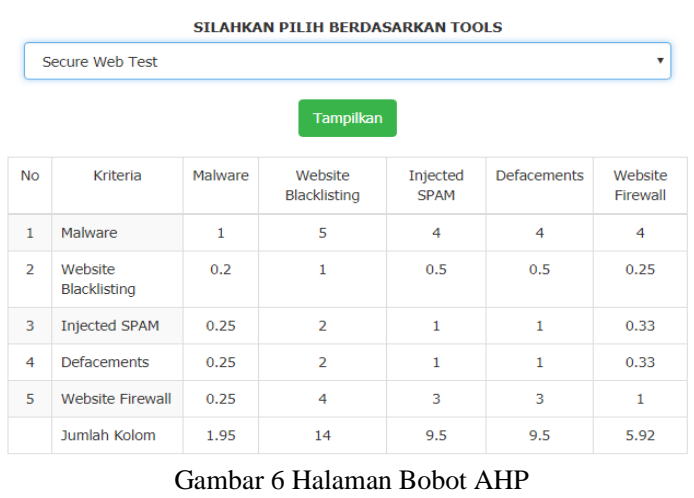

c. Halaman Konversi TFN

Halaman konversi tfn berfungsi untuk konversi bobot ahp ke Tringular Fuzzy Number (TFN), berikut adalah tampilan halaman konversi tfn.

\section{TS HASIL KONVERSI DALAM BENTUK LOW(L) MIDDLE(M) UPPER(U) KRITERIA}

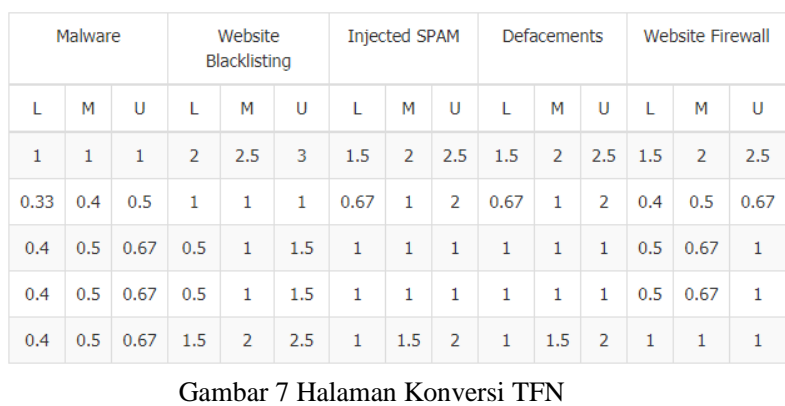

d. Halaman Perhitungan Fuzzy

Halaman perhitungan fuzzy berfungsi untuk proses penjumlah masing-masing titik, yaitu low, middle, dan upper. Normalisasi LMU yang diperoleh dari jumlah nilai low dibagi jumlah low, nilai middle dibagi jumlah middle, dan nilai upper dibagi jumlah upper. Bobot kriteria adalah hasil dari proses di atas, sehingga diperoleh bobot masing-masing kriteria, berikut adalah tampilan halaman perhitungan fuzzy.

\section{๖umlah L M U Masing-Masing Kriteria}

\begin{tabular}{|c|l|c|c|c|}
\hline No & \multicolumn{1}{|c|}{ Kriteria } & L & M & U \\
\hline 1 & Malware & 7.5 & 9.5 & 11.5 \\
\hline 2 & Website Blacklisting & 3.07 & 3.9 & 6.17 \\
\hline 3 & Injected SPAM & 3.4 & 4.17 & 5.17 \\
\hline 4 & Defacements & 3.4 & 4.17 & 5.17 \\
\hline 5 & Website Firewall & 4.9 & 6.5 & 8.17 \\
\hline & Jumlah Kolom & 22.27 & 28.24 & 36.18 \\
\hline
\end{tabular}

\section{Normalisasi L M U Masing - Masing Kriteria}

\begin{tabular}{|c|l|c|c|c|}
\hline No & Kriteria & L & M & U \\
\hline 1 & Malware & 0.337 & 0.336 & 0.318 \\
\hline 2 & Website Blacklisting & 0.138 & 0.138 & 0.171 \\
\hline 3 & Injected SPAM & 0.153 & 0.148 & 0.143 \\
\hline 4 & Defacements & 0.153 & 0.148 & 0.143 \\
\hline 5 & Website Firewall & 0.22 & 0.23 & 0.226 \\
\hline
\end{tabular}

\section{Bobot Kriteria}

\begin{tabular}{|c|l|c|}
\hline No & Kriteria & Bobot Masing-Masing Kriteria \\
\hline 1 & Malware & 0.33033 \\
\hline 2 & Website Blacklisting & 0.149 \\
\hline 3 & Injected SPAM & 0.148 \\
\hline 4 & Defacements & 0.148 \\
\hline 5 & Website Firewall & 0.22533 \\
\hline
\end{tabular}

Gambar 8 Halaman Perhitungan Fuzzy

e. Halaman Hasil Akhir (FAHP)

Halaman hasil akhir berfungsi untuk menampilkan hasil dari proses perkalian antara bobot prioritas kriteria dengan nilai prioritas $e$ commerce, dan penjumlahan dari nilai yang diperoleh, serta hasil perangkingan yang diurutkan secara descending, berikut adalah tampilan halaman hasil akhir.

Non Fuzzy Performance

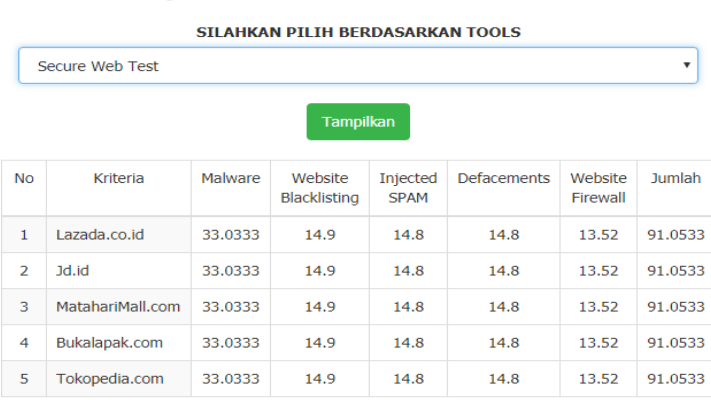

Gambar 9 Halaman Hasil Akhir 
f. Hasil Perangkingan dari tools Secure web Test (FAHP)

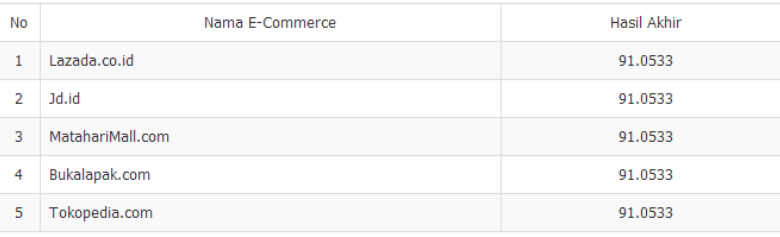

Gambar 10 Gambar Hasil Perangkingan Secure Web Test (FAHP)

g. Hasil Perangkingan AsafaWeb (FAHP)

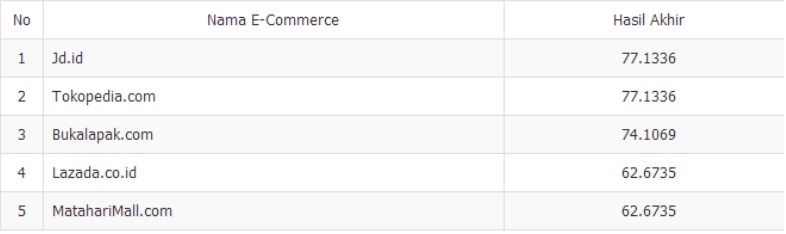

Gambar 11 Gambar Hasil Perangkingan AsafaWeb (FAHP)

h. Hasil Perangkingan Observatory by Mozilla (FAHP)

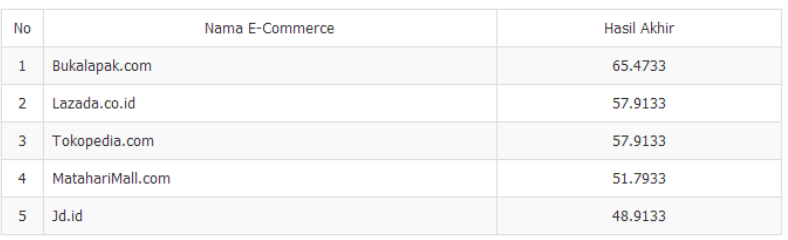

Gambar 12 Gambar Hasil Perangkingan Observatory by Mozilla (FAHP)

i. Analisa hasil metode FAHP

Tabel 3 Analisis Hasil Metode FAHP

\begin{tabular}{ccccc}
\hline \multirow{2}{*}{ No } & \multicolumn{2}{c}{ Nama $\boldsymbol{E}-$} & \multicolumn{3}{c}{ Hasil Akhir } \\
\cline { 3 - 5 } & Commerce & Secure & Asafa & Observatory \\
\hline 1. & Lazada & 91.0533 & 62.6735 & 57.9133 \\
2. & Jd & 91.0533 & 77.1336 & 48.9133 \\
3. & Mataharimall & 91.0533 & 62.6735 & 51.7933 \\
4. & Bukalapak & 91.0533 & 74.1069 & 65.4733 \\
5. & tokopedia & 91.0533 & 77.1336 & 57.9133 \\
\hline
\end{tabular}

j. Analisis Hasil Perangkingan (FAHP)

Tabel 4 Analisis Hasil Perangkingan (FAHP)

\begin{tabular}{llcccc}
\hline \multirow{2}{*}{ No } & \multirow{2}{*}{$\begin{array}{c}\text { Nama } \boldsymbol{E}- \\
\text { Commerce }\end{array}$} & Secure & $\begin{array}{c}\text { AsafaWe } \\
\boldsymbol{b}\end{array}$ & $\begin{array}{c}\text { Observat } \\
\text { ory }\end{array}$ & $\begin{array}{c}\text { Jumla } \\
\mathbf{h}\end{array}$ \\
\hline 1 & Lazada & 5 & 1 & 4 & 10 \\
2 & Jd.id & 5 & 5 & 1 & 11 \\
3 & Mataharimall & 5 & 2 & 2 & 9 \\
4 & Bukalapak & 5 & 1 & 5 & 11 \\
5 & Tokopedia & 5 & 5 & 4 & 14 \\
\hline
\end{tabular}

\section{Keterangan :}

Jika situs e-commerce berada pada peringkat 1 maka akan mendapat nilai 5, peringkat 2 mendapat nilai 4 , peringkat 3 mendapat nilai 3 , peringkat 4 mendapat nilai 2, dan peringkat 5 akan mendapatkan nilai 1 sedangkan jika ada nilai yang sama maka nilai yang diambil nilai tertinggi.
Tabel 3 menunjukkan hasil perangkingan yang diperoleh dari sistem yaitu situs tokopedia.com menduduki peringkat 1 dengan nilai akhir 14 , bukalapak.com dan jd.id menduduki peringkat ke 2 dengan nilai akhir 11, bukalapak menduduki peringkat ke 3 dengan nilai 10, sedangkan mataharimall menduduki peringkat 4 dengan nilai 9 .

\section{a. Analisa Akurasi}

Pada bagian ini akan dijelaskan tingkat keakuratan masing-masing tools, dimana tingkat kepentingan kriteria diperoleh dengan cara mencari faktor-faktor yang mempengaruhi terhadap website $e$ commerce. Berikut adalah hasil consistency ratio perbandingan kriteria pada masing-masing tools.

1. Secure Web Test

Pada gambar 13 dibawah ini adalah hasil consistency ratio dari tools secure web test yaitu 0.04, karena 0.04 kurang dari 0.1 maka bobot perbandingan kriteria sudah konsisten atau teruji keakuratannya.

\section{\#asil Perhitungan}

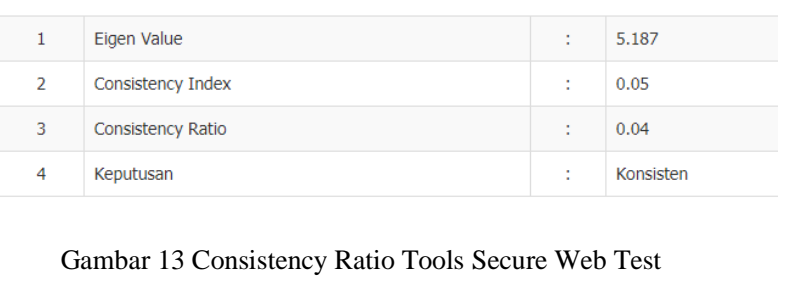

2. AsafaWeb

Pada gambar 14 dibawah ini adalah hasil consistency ratio dari tools AsafaWeb yaitu 0.00061, karena 0.00061 kurang dari 0.1 maka bobot perbandingan kriteria sudah konsisten atau teruji keakuratannya.

\section{囲 Hasil Perhitungan}

\begin{tabular}{|c|l|c|l|}
\hline 1 & Eigen Value & $:$ & 12.01053 \\
\hline 2 & Consistency Index & $:$ & 0.00096 \\
\hline 3 & Consistency Ratio & $:$ & 0.00061 \\
\hline 4 & Keputusan & $:$ & Konsisten \\
\hline
\end{tabular}

Gambar 14 Consistency Ratio Tools AsafaWeb

\section{Observatory by Mozilla}

Pada gambar 15 dibawah ini adalah hasil consistency ratio dari tools Observatory by Mozilla yaitu 0.00148 , karena 0.00148 kurang dari 0.1 maka bobot perbandingan kriteria sudah konsisten atau teruji keakuratannya.

\section{囲 Hasil Perhitungan}

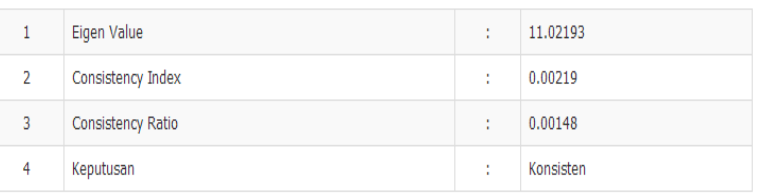

Gambar 15 Consistency Ratio Tools Observatory by Mozilla 
Konsistensi atau keakuratan dari penilaian berpasangan dievaluasi dengan menghitung Consistency Ratio (CR). Saaty menetepkan apabila $\mathrm{CR} \leq 0,1$ maka penilaian dikatakan konsisten. Dari penilaian yang dilakukan ketiga tools di atas dapat disimpulkan bahwa tools tersebut sudah konsistensi, karena Consistency Ratio (CR) kurang dari 0,1.

k. Analisa hasil metode AHP

Tabel 5 Analisis Hasil Metode AHP

\begin{tabular}{|c|l|c|c|c|}
\hline \multirow{2}{*}{$\begin{array}{c}\text { N } \\
\text { o }\end{array}$} & Nama $\boldsymbol{E}-$ & \multicolumn{3}{|c|}{ Hasil Akhir } \\
\cline { 3 - 5 } Commerce & Secure & Asafa & Observatory \\
\hline 1. & Lazada & 90.2839 & 66.62 & 57.91 \\
\hline 2. & Jd & 90.2839 & 82.57 & 48.91 \\
\hline 3. & Mataharimall & 90.2839 & 66.62 & 51.79 \\
\hline 4. & Bukalapak & 90.2839 & 75.33 & 65.47 \\
\hline 5. & tokopedia & 90.2839 & 82.57 & 57.91 \\
\hline
\end{tabular}

1. Perangkingan metode AHP

Tabel 6 Perangkingan Metode AHP

\begin{tabular}{|c|l|c|c|c|c|}
\hline \multirow{2}{*}{$\begin{array}{c}\text { N } \\
\text { o }\end{array}$} & \multirow{2}{*}{\begin{tabular}{c} 
Nama Commerce \\
\cline { 3 - 5 }
\end{tabular}} & $\begin{array}{c}\text { Secur } \\
\boldsymbol{e}\end{array}$ & Asafa & $\begin{array}{c}\text { Observ } \\
\text { atory }\end{array}$ & $\begin{array}{c}\text { Juml } \\
\text { ah }\end{array}$ \\
\hline 1. & Lazada.co.id & 5 & 1 & 4 & 10 \\
\hline 2. & Jd.id & 5 & 5 & 1 & 11 \\
\hline 3. & $\begin{array}{l}\text { Mataharimal } \\
\text { l.com }\end{array}$ & 5 & 2 & 2 & 9 \\
\hline 4. & $\begin{array}{l}\text { Bukalapak.c } \\
\text { om }\end{array}$ & 5 & 1 & 5 & 11 \\
\hline 5. & $\begin{array}{l}\text { Tokopedia.c } \\
\text { om }\end{array}$ & 5 & 5 & 4 & 14 \\
\hline
\end{tabular}

Keterangan :

Jika situs $e$-commerce berada pada peringkat 1 maka akan mendapat nilai 5, peringkat 2 mendapat nilai 4 , peringkat 3 mendapat nilai 3 , peringkat 4 mendapat nilai 2, dan peringkat 5 akan mendapatkan nilai 1 sedangkan jika ada nilai yang sama maka nilai yang diambil nilai tertinggi.

Tabel diatas menunjukkan hasil perangkingan yang diperoleh dari sistem yaitu situs tokopedia.com menduduki peringkat 1 dengan nilai akhir 14 , bukalapak.com dan jd.id menduduki peringkat ke 2 dengan nilai akhir 11, bukalapak menduduki peringkat ke 3 dengan nilai 10 , sedangkan mataharimall menduduki peringkat 4 dengan nilai 9 .

\section{KESIMPULAN DAN SARAN}

Dari hasil penelitian yang telah dilakukan, dapat ditarik kesimpulan sebagai berikut :

1. Metode Analytical Hierarchy Process dan Fuzzy Analytical Hierarchy Process dapat mengurutkan ecommerce secara descending berdasarkan perbandingan kriteria dan nilai ecommerce yang diperoleh dari hasil scan tools web security.
2. Hasil akhir metode AHP dan FAHP untuk perangkingan e-commerce sama persis, meskipun ada sedikit perbedaan pada score akhirnya.

3. Dari 3 tools yang dipakai, diketahui bahwa Tokopedia.com sebagai $e$-commerce terbaik dalam segi keamanan website, karena tokopedia berada pada rangking 1 pada 1 tools web security, yaitu sucure web test, tools asafaweb menduduki rangking 2, dan pada tools observatory berada pada rangking 2.

4. Dari perhitungan yang telah dilakukan, perangkingan yang diperoleh dari sistem yaitu situs tokopedia.com menduduki peringkat 1 dengan nilai akhir 14, bukalapak.com dan jd.id menduduki peringkat ke 2 dengan nilai akhir 11, bukalapak menduduki peringkat ke 3 dengan nilai 10, sedangkan mataharimall menduduki peringkat 4 dengan nilai 9 .

Berdasarkan penelitian yang telah dilakukan, masih terdapat kekurangan yang dapat ditambahkan di penelitian selanjutnya, antara lain tools yang dipakai dapat ditambahkan agar hasil perangkingan menjadi lebih akurat.

\section{DAFTAR PUSTAKA}

IRMAWATI D. 2011. Pemanfaatan E-Commerce dalam dunia bisnis. ISSN: 2005-1375. Palembang. Politeknik Negeri Sriwijaya.

R. MERWE \& BEKKER, "A Framework and Methodology for Evaluating E-Commerce Web Sites" Internet Research : Electronic Networking Applications and Policy, vol. 13, pp. 330-341, 2003.

ONGKOWIJOYO S. 2013. Model Penilaian Keamanan Situs Web ECommerce Menggunakan Kombinasi Metode Ahp, Dempster Shafer Dan Fuzzy Topsis (Tesis). Semarang. Universitas Diponegoro Semarang.

CHANG, D. Y. 1996. Aplication of the Extent Analysis Method on Fuzzy AHP. European Journal of Operational Research 95, 649655.

RAHARDIAN R, Hidayat N, Dewi R K, 2018, Sistem Pendukung Keputusan Penentuan Penerima Bantuan Keluarga Miskin Menggunakan Metode Analytical Hierarchy Process Preference Ranking Organization for Enrichment Evaluaion II (AHPPROMETHEE II), Vol. 2, hal 1980-1985, eISSN: 2548-964X, Malang, Universitas Brawijaya. 
380 Jurnal Teknologi Informasi dan Ilmu Komputer (JTIIK), Vol. 5, No. 3, Agustus 2018, hlm. 371-380

ANWARININGSIH S H, Multi Faktor Kualitas Website. Surakarta. Universitas Sahid Surakrta.

KUSTIYAHNINGSIH YENI, DKK. 2016. Integration balanced scoredcard and fuzzy Analytic network process (fanp) for measuring Performance of small medium enterprise (sme). Bangkalan. Universitas Trunojoyo Madura.

FAISOL A, MUSLIM M A, SUYONO H. 2014. Komparasi Fuzzy AHP dengan AHP pada Sistem Pendukung Keputusan Investasi Properti. Malang. Universitas Brawijaya Malang. 